\title{
Effect of SARS-CoV-2 infection on semen parameters
}

\author{
Mustafa Bilal Hamarat, MD'; Mehmet Serkan Ozkent, MD'; Burak Yilmaz, MD'; Salih Yahya Aksanyar, MD; \\ Kadir Karabacak, $M D^{1}$
}

'Department of Urology, University of Health Sciences University, Konya City Hospital, Konya, Uurkey; ${ }^{2}$ Department of Embryology, University of Health Sciences, Konya City Hospital, Konya, Turkey

Cite as: Hamarat MB, Ozkent MS, Yilmaz B, et al. Effect of SARS-CoV-2 infection on semen parameters. Can Urol Assoc J 2022;16(3):E173-7. http://dx.doi.org/10.5489/cuaj.7292

Published online October 18, 2021

\section{Abstract}

Introduction: In this study, we aimed to assess the effect of SARSCoV-2 infection on semen parameters in one group of patients before and after infection.

Methods: Patients were screened if they had a semen analysis performed between October 1, 2019, and December 1, 2020, in the assisted reproduction unit and later had positive polymerase chain reaction (PCR) test for SARS-CoV-2 infection. The patients' semen parameters were recorded before and after SARS-CoV-2 infection, along with degrees of SARS-CoV-2 infection, dates of SARS-CoV-2 infection, durations between the treatment for SARSCoV-2 infection and the second semen analysis, time of symptom onset, duration of their symptoms, ages, comorbidities, and any medications patients were taking.

Results: Forty-one patients were included in the study. The mean age of the patients was $31.29 \pm 5.95$ years. The mean duration from first semen analysis to the PCR test was $7.74 \pm 3.03$ months. The mean duration between the PCR test and later semen analysis was $2.35 \pm 1.35$ months. The median sperm concentration for the patients before and after SARS-CoV-2 infection were $24 \mathrm{mil} / \mathrm{ml}$ and $13 \mathrm{mil} / \mathrm{ml}$, respectively $(\mathrm{p}<0.001)$. The normal morphology percentage before infection was $3.16 \pm 0.92$, while it was $2.44 \pm 1.04$ after infection $(p=0.011)$. In 26 patients, the period from the time of infection to the second semen analysis was over 70 days, while this period was less than 70 days in the other 15 patients. In both patient groups, a significant decrease was detected in the sperm concentrations and total sperm count.

Conclusions: In the semen samples we assessed, we observed a significant decrease in the mean sperm concentration, total sperm count, and mean percentage of samples with normal morphology after SARS-CoV-2 infection.

\section{Introduction}

The first case of a novel coronavirus disease was observed in Wuhan City, China, in 2019, and following this, it spread around the world. ${ }^{1}$ It has been proposed that the severe acute respiratory syndrome coronavirus-2 (SARS-CoV-2) causes cell injury to the transmembrane serine protease 2 (TMPRSS2) enzyme, which binds to the angiotensin-converting enzyme 2 (ACE2) receptor that is expressed in many organs, including the testes. ${ }^{2}$ The virus binds to ACE2 through "the spike protein" it contains. Following entry, it starts a proinflammatory process and cause cell damage. The primarily targeted tissues are respiratory epithelia, which highly express ACE2. ${ }^{3}$ In addition, the testes, which expresses high amounts of ACE2 mRNA in seminiferous tubule cells, spermatogonia, Leydig cells, and Sertoli cells, may be an important target., ${ }^{4,5}$ ACE improves Leydig and Sertoli cells and plays a significant role in the regulation of spermatogenesis. In addition, it is recognized as a regulator of the sperm cell function and epididymal contractility. ${ }^{6}$ Thus, a number of studies have stated that the increased inflammatory response and linked oxidative stress that develops in SARS-CoV-2 infection may cause loss of function in the testes. ${ }^{7,8}$

Although many studies have been performed on the effect of SARS-CoV-2 on reproductive health in the shortterm vs. healthy controls, there is a paucity of data showing the degree to which the virus affects the semen parameters in one group of patients after coronavirus infection compared to before infection. In this study, we aimed to assess the effect of SARS-CoV-2 infection on semen parameters by investigating sperm parameters in male patients who experienced this infection.

\section{Methods}

The Ethics Committee of The Konya Chamber of Commerce Karatay University Karatay Faculty of Medicine approved this study (E-41901325-050.99-693). Patients were screened if they had a semen analysis performed between October 1, 2019, and December 1, 2020, in the assisted reproduction unit and later had positive polymerase chain reaction (PCR) tests for SARS-CoV-2 infection. These patients consisted of those who had previously been examined in the urology outpatient clinic for infertility or varicocele. Patients were 
contacted by telephone and given appointments with the assisted reproduction unit to provide semen samples. Semen analysis was performed on the patients after three days of sexual abstinence. Patients were excluded from the study if they were under 18 years of age, had azoospermia, had any urogenital operations in this period, had undergone assisted reproduction techniques, were using steroids for infection treatment, or were using medications that could affect semen parameters (testosterone, supplements, antibiotics, etc.). The patients' semen parameters were recorded before and after SARS-CoV-2 infection, along with degrees of SARS-CoV-2 infection, dates of SARS-CoV-2 infection, durations between the treatment for SARS-CoV-2 infection and the second semen analysis, time of symptom onset, durations of symptoms, ages, comorbidities, and any medications they were taking. Patients who were treated at home were recorded as having mild infection; those admitted to the hospital with oxygen requirements were recorded as having moderate infection; and patients treated in the intensive care unit were recorded as having severe infection. ${ }^{9}$

Semen analysis was performed by liquidizing ejaculate, obtained through masturbation after three days of sexual abstinence in a sterile container, for 30-60 minutes at room temperature and then investigating this under a microscope. Semen analysis was performed by the same embryologist, according to the World Health Organization (WHO) and Kruger's criteria. ${ }^{10}$ Analysis included sperm concentration, total sperm count, semen volume, sperm motility (progressive motility, non-progressive motility, and immotility percentages), and morphological features of the sperm (determined as normal morphology percentage in addition to head, neck, and tail anomaly percentages). Leukocytes and round cells were counted manually and microscopically by the embryologist (i.e., no peroxidase test performed).

\section{Statistical analyses}

SPSS (Version 23) was used for statistical analysis. With this software, the mean age and body mass index of the patients are given as means \pm standard deviations. Data adhering to normal distribution and parametric data are expressed as means and standard deviations. Data that do not meet parametric distribution criteria are given as median and interquartile ranges. The paired t-test or Wilcoxon test was used for comparative analysis of sperm parameters before and after SARS-CoV-2 infection in the patients. Values with $\mathrm{p}<0.05$ were accepted as statistically significant.

\section{Results}

A total of 79 patients who had semen analysis in our assisted reproduction center and later had positive SARS-CoV-2 PCR tests were identified. These patients were contacted by tele- phone, and 46 patients who had no treatment for infertility attended our center to provide sperm samples. The data for these 46 patients were recorded. Of these patients, five were excluded from the study: two had azoospermia and three had undergone genital operations. Therefore, a total of 41 patients were included in the final study.

Semen analysis was originally performed in seven of these patients for varicocele, 25 for primary infertility, and nine for secondary infertility. The mean age of the patients was 31.29 \pm 5.95 years. One patient had hypertension, one had asthma; all others had no comorbid diseases. Only two patients had moderate infection, while 39 had mild infection. The onset of symptoms was an average of $4.03 \pm 1.48$ (2-7) days before the PCR test, and the symptoms lasted an average of $7.22 \pm 1.96(5-12)$ days. All patients stated they had fever at least once, and no patient reported a fever above 38.5 degrees, except for two hospitalized patients, who had fever of up to 39.5 degrees. After their diagnosis, all patients received 40 tablets of favipiravir (200 mg favicovir/ tablet) for five days, along with vitamin $\mathrm{C}$ and parol treatment if necessary. The mean duration from the first semen analysis to the PCR test was $7.74 \pm 3.03$ months. The mean duration between the PCR test and later semen analysis was $2.35 \pm 1.35$ months. Table 1 shows the demographic characteristics of the patients.

The median sperm concentrations for the patients before and after SARS-CoV-2 infection were $24 \mathrm{mil} / \mathrm{ml}$ and $13 \mathrm{mil} /$ $\mathrm{ml}$, respectively $(\mathrm{p}<0.001)$. The normal morphology percentage before SARS-CoV-2 infection was 3.16 \pm 0.92 , while it was $2.44 \pm 1.04$ after infection $(p=0.011)$. Table 2 provides the semen parameters for patients before and after SARS-CoV-2 infection, with 13 patients having oligospermia before SARSCoV-2 infection and 18 having oligospermia after infection.

\begin{tabular}{lc}
\hline Table 1. Demographic characteristics of the patients \\
\hline Number of patients & 41 \\
Age (years), mean \pm SD (min-max) & $31.29 \pm 5.95$ \\
& $(22-46)$ \\
Body mass index, mean \pm SD (min-max) & $23.21 \pm 2.05$ \\
& $(18.8-26.2)$ \\
Comorbidity, $\mathrm{n}$ & 1 \\
Hypertension & 1 \\
Asthma & 39 \\
Mild infection, $\mathrm{n}$ & 2 \\
Moderate infection, $\mathrm{n}$ & - \\
Severe infection, $\mathrm{n}$ & $7.74 \pm 3.03(1-11)$ \\
Time from the first semen analysis to the PCR & \\
test (months), mean \pm SD (min-max) & $2.35 \pm 1.35$ (1-8) \\
Time from PCR test to second semen analysis \\
(moths) (mean \pm SD) (min-max) \\
Time from PCR test to second semen analysis, $\mathrm{n}$ \\
$\quad<70$ days \\
$\quad>70$ days \\
\hline PCR: polymerase chain reaction; SD: standard deviation.
\end{tabular}


In 26 patients, the period from the time of infection to the second semen analysis was over 70 days, while this period was less than 70 days in the other 15 patients. In the semen analysis performed after infection in both these patient groups, a significant decrease was detected in the sperm concentrations and total sperm counts. In addition, a significant decrease was found in the normal morphology percentages in the group for whom the time of infection to second semen analysis was less than 70 days.

The number of patients with more than five million round cells in the semen parameter was three before SARS-CoV-2 infection; this number was six after infection. In addition, the leukocytes were above one million on the semen parameters of three patients before SARS-CoV-2, and these three patients had leukocytes above one million after infection. Agglutination was not observed on the semen parameters of any patient before SARS-CoV-2 infection, while one patient had grade 4 agglutination after SARS-CoV-2 infection.

\section{Discussion}

Studies have shown that many viruses, such as human papilloma virus (HPV), herpes simplex virus (HSV), mumps virus, human immunodeficiency virus (HIV), hepatitis B virus, hepatitis $C$ virus, and Coxsackie virus, negatively affect the reproductive system and semen quality. ${ }^{11,12}$ Although the mechanism by which viruses damage the testes is not clearly known, different hypotheses have been proposed. Viruses may directly enter the testes and cause testicular damage.
Moreover, the immune response directed against viruses and the resulting inflammation and increase in temperature may damage the testicular tissue. ${ }^{13}$

In 2006, Xu et al showed that SARS-CoV-1 could cause testicular damage. Subsequently, the number of studies on the effects of SARS-CoV-2 on the genital system and semen quality has rapidly increased. ${ }^{14}$ Pan et al did not detect SARSCoV-2 in the semen samples of patients collected nearly one month after recovery from SARS-CoV-2 infection. ${ }^{15}$ However, $\mathrm{Li}$ et al detected SARS-CoV-2 in semen samples from patients in the acute phase of infection and early recovery. ${ }^{16}$

Theoretically, SARS-CoV-2 may affect all cells that have ACE2 receptors and express TMPRSS2. The ACE2 mRNA and protein expression levels in the testes are higher than those in many other tissues; this increases the probability of damage by the virus. ${ }^{4}$ One of the most important functions of the testes is to produce sperm and infections may deteriorate sperm quality. In the present study, we investigated the effect of SARS-CoV-2 on semen parameters by comparing the semen parameters of patients before and after infection and observed significant changes in the sperm count and morphology.

Yang et al examined the testes of 12 patients who died of SARS-CoV-2 infection. They observed normal spermatogenesis in three samples, but noted spermatogenesis defects in the rest. ${ }^{17} \mathrm{Li}$ et al assessed the semen parameters of 23 patients who had recovered from SARS-CoV2 infection and found that their mean sperm count was 11.9 million; this count was 40.9 million in healthy controls belonging to a

Table 2. Comparison of semen parameters before and after SARS-CoV-2 infection

\begin{tabular}{|c|c|c|c|c|c|c|c|c|c|}
\hline & $\begin{array}{l}\text { Before } \\
\text { SARS- } \\
\text { CoV-2 } \\
\text { infection }\end{array}$ & $\begin{array}{l}\text { After SARS- } \\
\text { CoV-2 } \\
\text { infection }\end{array}$ & & $\begin{array}{l}\text { Before } \\
\text { SARS- } \\
\text { CoV-2 } \\
\text { infection }\end{array}$ & $\begin{array}{l}\text { After SARS- } \\
\text { CoV-2 } \\
\text { infection }\end{array}$ & & $\begin{array}{l}\text { Before } \\
\text { SARS- } \\
\text { CoV-2 } \\
\text { infection }\end{array}$ & $\begin{array}{l}\text { After SARS- } \\
\text { CoV-2 } \\
\text { infection }\end{array}$ & \\
\hline & $<70$ days & $<70$ days & p & >70 days & $>70$ days & $\mathbf{p}$ & Total & Total & p \\
\hline Patients (n) & 15 & 15 & & 26 & 26 & & 41 & 41 & \\
\hline $\begin{array}{l}\text { Volume }(\mathrm{ml}) \text {, mean } \\
\pm \mathrm{SD}\end{array}$ & $2.67 \pm 0.79$ & $2.51 \pm 0.81$ & $0.347^{*}$ & $2.58 \pm 1.55$ & $2.26 \pm 1.16$ & $0.128^{*}$ & $2.61 \pm 1.25$ & $2.35 \pm 1.03$ & $0.069 *$ \\
\hline $\begin{array}{l}\text { Sperm concentration } \\
\text { (mil/ml), median } \\
(\mathrm{min}-\mathrm{max})\end{array}$ & $20(4-73)$ & $9(1-18)$ & $0.008^{* *}$ & $42(2-93)$ & $30(0.1-63)$ & $0.010 * *$ & $24(2-93)$ & $13(0.1-63)$ & $<0.001 * *$ \\
\hline $\begin{array}{l}\text { Total sperm number } \\
\text { (million, median } \\
\text { (min-max) }\end{array}$ & $53.5(5-219)$ & $20.75(2.5-72)$ & $0.013^{* *}$ & $67.2(3-318)$ & $40.3(0.4-168)$ & $<0.001 * *$ & $63(3-318)$ & $28.8(0.4-168)$ & $<0.001^{* *}$ \\
\hline Progressive motility & $29.05 \pm 8.44$ & $27,35 \pm 12.21$ & $0.660 *$ & $36.23 \pm 15.53$ & $32.70 \pm 13.78$ & $0.251^{*}$ & $33.66 \pm 13.59$ & $30.74 \pm 14.28$ & $0.230 *$ \\
\hline Total motility (\%) & $37.01 \pm 9.68$ & $35.63 \pm 16.70$ & $0.761^{*}$ & $44.88 \pm 17.74$ & $40.47 \pm 16.39$ & $0.194^{*}$ & $42 \pm 15.52$ & $38.70 \pm 16.35$ & $0.215^{*}$ \\
\hline Immotility (\%) & $62.98 \pm 9.68$ & $64.34 \pm 16.70$ & $0.761^{*}$ & $55 \pm 17.67$ & $59.47 \pm 16.48$ & $0.189^{*}$ & $57.92 \pm 15.48$ & $61.25 \pm 16.41$ & $0.211^{*}$ \\
\hline $\begin{array}{l}\text { Normal morphology } \\
(\%)\end{array}$ & $2.99 \pm 1.15$ & $1.85 \pm 1.06$ & $0.030 *$ & $3.27 \pm 0.78$ & $2.81 \pm 0.87$ & $0.176^{*}$ & $3.16 \pm 0.92$ & $2.44 \pm 1.04$ & $0.011^{*}$ \\
\hline Head anomaly (\%) & $85.48 \pm 2.76$ & $88.21 \pm 4.37$ & $0.170^{*}$ & $83 \pm 1.73$ & $84.54 \pm 3.11$ & $0.161^{*}$ & $83.94 \pm 2.43$ & $85.94 \pm 3.96$ & $0.040^{*}$ \\
\hline Neck anomaly (\%) & $2.85 \pm 0.89$ & $2.52 \pm 0.78$ & $0.457^{*}$ & $3.09 \pm 0.83$ & $3.36 \pm 0.67$ & $0.465^{*}$ & $3.00 \pm 0.84$ & $3.05 \pm 0.80$ & $0.830^{*}$ \\
\hline Tail anomaly (\%) & $10.51 \pm 3.10$ & $8.18 \pm 4.88$ & $0.199 *$ & $13 \pm 2.86$ & $11.36 \pm 3.10$ & $0.127^{*}$ & $12.05 \pm 3.11$ & $10.16 \pm 4.06$ & $0.037^{*}$ \\
\hline
\end{tabular}


similar age group. In their study, in the SARS-CoV-2 patient group, nine patients were found to have oligospermia. ${ }^{18}$

To date, studies have compared the semen parameters of patients after SARS-CoV-2 infection with those of a demographically similar control group; however, no study has compared the semen parameters of one group of patients before and after infection. In the present study, semen analyses performed $2.35 \pm 1.35$ months after SARS-CoV-2 infection revealed that the median sperm concentration was 24 (2-93) $\mathrm{mil} / \mathrm{ml}$ before infection and $13(0.1-63) \mathrm{mil} / \mathrm{ml}$ after infection $(p<0.001)$. In addition, oligospermia was identified in 13 patients before SARS-CoV-2 infection, and in 18 patients after infection. Moreover, the mean percentages of samples with normal morphology and tail anomaly were significantly lower after infection than before infection. On the other hand, the percentage of samples with head anomalies significantly increased after infection. Although the mean percentage of total motile sperm decreased after infection, the difference was not statistically significant.

It is proposed that inflammation-mediated testicular damage may cause infertility. ${ }^{19} \mathrm{Xu}$ et al identified orchitis during the testes autopsies of six patients who died of infection due to SARS-CoV- 1 , which is $85 \%$ similar to SARS-CoV- 2 . Moreover, they noted leukocyte infiltration that may damage the Leydig cells, blood-testes barrier, and seminiferous tubules in the testes. Although these findings were noted on autopsy, the patients did not have symptoms of orchitis during their clinical followup when they were alive. ${ }^{14}$ However, Özveri et al reported normal semen parameters on analyzing the semen of a SARS-CoV-2 patient who visited the hospital only with symptoms of orchitis. ${ }^{20}$ In the present study, no significant change was noted in the leukocyte counts in the semen samples before and after infection; only three patients $(7.3 \%)$ stated that they experienced testicular pain during SARS-CoV-2 infection.

It has been suggested that while focal edema, diffuse alveolar damage, and pneumonia develop in the lungs in the early period due to the SARS-Cov-2 infection, the virus may cause permanent damage by causing the development of fibrosis in the lungs in the late period. ${ }^{21}$ Virus-related fever, inflammation, and antiviral drugs used in the treatment may cause spermatogenesis defects in the early period by damaging the germ cells. In addition, the SARS-Cov-2 virus can cause permanent damage to the testes, similar to the pathophysiology suggested in the lung. Inflammatory cytokines, which increase due to the immune response to the virus, may cause deterioration of the blood-testicular barrier and damage to the testes. Increased expression of ACE2 in Sertoli, Leydig, and germ cells, especially in men of reproductive age, may make these cells more vulnerable to the virus. ${ }^{22}$

Our patients were separated into two groups to understand whether the deterioration in semen parameters that we observed was caused by an early temporary spermatogenesis defect or a late period spermatogenesis defect. While a significant decrease in sperm concentrations and total sperm counts was noted in all patients, those for whom time of infection to second semen analysis was less than 70 days also showed a significant decrease in normal morphology percentage. Continuing deterioration in semen parameters in the late period after SARS-Cov-2 infection may be caused by permanent damage due to the virus. Future studies to include longitudinal studies on post-infection men are needed to show the long-term effect of infection.

The greatest limitation of this study was that the effect of medications used in our country for SARS-CoV-2 infection on semen parameters were not clearly known. Additional limitations included not having a peroxidase test in semen analysis, the relatively low number of patients included in the study, and the fact that nearly all patients had mild SARSCoV-2 infection.

\section{Conclusions}

We observed a significant decrease in the mean sperm concentration, total sperm count, and mean percentage of samples with normal morphology after SARS-CoV-2 infection in our cohort. There is a need for more studies showing the long-term effects of SARS-CoV-2 infection on semen parameters and fertility.

Competing interests: The authors do not report any competing personal or financial interests related to this work.

This paper has been peer-reviewed.

\section{References}

1. Guan W-j, Ni Z-y, Hu Y, et al. Clinical characteristics of coronavirus disease 2019 in China. N Engl J Med 2020;382:1708-20. hitps://doi.org/10.1056/NEJMoa2002032

2. Chen Y, Guo Y, Pan Y, et al. Structure analysis of the receptor binding of 2019-nCoV. Biochem Biophys Res Comm 2020;525:135-40. htrps://doi.org/10.1016/i.bbrc.2020.02.071

3. Li R, Yin T, Fang F, et al. Potential risks of SARS-CoV-2 infection on reproductive health. Reproduct Biomed Online 2020;41:89-95. https://doi.org/10.1016/i.rbmo.2020.04.018

4. Fan C, Li K, Ding Y, et al. ACE2 expression in kidney and testis may cause kidney and testis infection in COVID-19 patients. Front Med 2021;7:563893. https://doi.org/10.3389/fmed.2020.563893

5. Wang $Z, X \cup X$. scRNA-seq profiling of human testes reveals the presence of the ACE2 receptor, a target for SARS-CoV-2 infection in spermatogonia, Leydig and Sertoli cells. Cells 2020;9:920. https://doi.org/10.3390/cells9040920

6. Pan P-P, Zhan Q-T, Le F, et al. Angiotensin-converting enzymes play a dominant role in fertility. Int J Moled Sci 2013;14:21071-86. hitps://doi.org/10.3390/iims141021071

7. Mohamad N-V, Wong SK, Hasan WNW, et al. The relationship between circulating testosterone and inflammatory cytokines in men. Aging Male 2019;22:129-40. https://doi.org/10.1080/136855 38.2018 .1482487

8. Maggio M, Basaria S, Ceda G, et al. The relationship between testosterone and molecular markers of inflammation in older men. J Endocrinol Invest 2005;28:116-9. https://doi.org/10.1007/BF03347554

9. Holtmann N, Edimiris P, Andree M, et al. Assessment of SARS-CoV-2 in human semen-a cohort study. Fertil Steril 2020;114:233-8. https://doi.org/10.1016/j.fertnstert.2020.05.028 
10. World Health Organization. WHO laboratory manual for the examination and processing of human semen, Fifth Edition. 2010. Available at: https://www.who.int/docs/default-source/reproductive-health/sthrdocuments/infertility/examination-and-processing-of-human-semen-5ed-eng.pdf. Accessed 0ct. 18, 2021

11. Batiha 0, Al-Deeb T, Al-Zoubi E, et al. Impact of COVID-19 and other viruses on reproductive health. Andrologia 2020;52:e13791. https://doi.org/10.1111/and.13791

12. Kharbach Y, Khallouk A. Male genital damage in COVID-19 patients: Are available data relevant? Asian J Urol 2021;8:324-6. https://doi.org/10.1016/i.auur.2020.06.005

13. Dejucq N, Jégou B. Viruses in the mammalian male genital tract and their effects on the reproductive system. Microbio Molec Bio Rev 2001;65:208-31. https://doi.org/10.1128/MMBR.65.2.208-231.2001

14. Xu J, Qi L, Chi X, et al. Orchitis: A complication of severe acute respiratory syndrome (SARS). Bio Reprod 2006;74:410-6. https://doi.org/10.1095/biolreprod.105.044776

15. Pan F, Xiao X, Guo J, et al. No evidence of severe acute respiratory syndrome-coronavirus 2 in semen of males recovering from coronavirus disease 2019. Fertil Steril 2020;113:1135-9. https://doi.org/10.1016/i.fertnstert.2020.04.024

16. Li D, Jin M, Bao P, et al. Clinical characteristics and results of semen tests among men with coronavirus disease 2019. JAMA Network Open 2020;3:e208292-e. https://doi.org/10.1001/jamanetworkopen.2020.8292
17. Yang $M$, Chen $S$, Huang $B$, et al. Pathological findings in the testes of COVID-19 patients: clinical implications. Eur Urol Focus 2020;6:1124-9. hitps://doi.org/10.1016/i.euf.2020.05.009

18. Li H, Xiao X, Zhang J, et al. Impaired spermatogenesis in COVID-19 patients. EClinicalMedicine 2020;28:100604. https://doi.org/10.1016/i.edinm.2020.100604

19. Illiano E, Trama F, Costantini E. Could COVID-19 have an impact on male fertility? Andrologia 2020;52:e13654. https://doi.org/10.1111/and.13654

20. Özveri H, Eren MT, Krrişoğlu CE, et al. Atypical presentation of SARS-CoV-2 infection in male genitalia. Urol Case Rep 2020;33:101349. hrtps://doi.org/10.1016/i.eucr.2020.101349

21. Mo X, Jian W, Su Z, et al. Abnormal pulmonary function in COVID-19 patients at time of hospital discharge. Eur Resp J 2020;55:2001217. https://doi.org/10.1183/13993003.01217-2020

22. Shen $Q$, Xiao $X$, Aierken A, et al. The ACE2 expression in Sertoli cells and germ cells may cause male reproductive disorder after SARS-CoV-2 infection. J Cell Molec Med 2020;24:9472-7. https://doi.org/10.1111/icmm.15541

Correspondence: Dr. Mustafa Bilal Hamarat, Department of Urology, University of Health Sciences University, Konya City Hospital, Konya, Turkey; bilalhamarat@gmail.com 